\title{
A CLINICO-EPIDEMIOLOGICAL STUDY OF PAEDIATRIC LEPROSY IN A TERTIARY CARE CENTRE
}

\author{
Mariaviagulam Vinnarasan1, Krishnamorrthy Vinothiney22, Balaji Gopalan³, Sindhuja Ramasamy4 \\ ${ }_{1}^{1}$ Assistant Professor, Department of Dermatology, Thanjavur Medical College, Thanjavur, Tamilnadu. \\ $21^{\text {st }}$ Year Postgraduate Student, Department of Dermatology, Thanjavur Medical College, Thanjavur, Tamilnadu. \\ ${ }^{3}$ Senior Assistant Professor, Department of Neurology, Chengelpet Medical College, Chengelpet, Tamilnadu. \\ ${ }_{4}^{4}$ Associate Professor, Department of Dermatology, Villupuram Medical College, Tamilnadu.
}

\section{ABSTRACT}

\section{BACKGROUND}

Leprosy is a major public health problem in developing countries. India dominates the global picture with $60 \%$ of the world's leprosy cases. Although, the prevalence has fallen due to a combination of effective antibiotic therapy, incidence of leprosy remains stable with high rates of childhood cases.

Aims and Objectives- The main objective of this study was to analyse the clinico-epidemiological features and prevalence of paediatric leprosy in our tertiary care centre.

\section{MATERIALS AND METHODS}

This study is a retrospective descriptive study, a hospital-based analytical study that includes 39 self-reporting patients of age group 3 - 15 years who attended the Dermatology OP for 1 year from March 2017 to February 2018 in our medical college situated in South India. A complete history and detailed cutaneous and peripheral nerve examination were carried out in all patients. Relevant investigations were done wherever necessary.

\section{RESULTS}

The study yielded 39 paediatric cases of leprosy. The age of childhood leprosy cases ranges from 3 - 12 years. There were 28 male children and 11 female children. Most of the cases were multibacillary type. Family history of leprosy was present in 11 cases and all the family members were of lepromatous leprosy type.

\section{CONCLUSION}

Data correlates with previous hospital-based prevalence studies of paediatric leprosy. The clinical, bacteriological and histopathological characteristics of leprosy cases in children, especially the high percentage of multibacillary cases evidently indicate the grave nature of the problem of undetected childhood leprosy, recent active transmission of disease in the community.

\section{KEY WORDS}

Paediatric Leprosy, Prevalence, Clinico-Epidemiological Profile.

HOW TO CITE THIS ARTICLE: Vinnarasan M, Vinothiney K, Gopalan B, et al. A clinico-epidemiological study of paediatric leprosy in a tertiary care centre. J. Evolution Med. Dent. Sci. 2018;7(21):2558-2561, DOI: 10.14260/jemds/2018/576

\section{BACKGROUND}

Leprosy is a chronic granulomatous disease caused by Mycobacterium leprae affecting all age groups, primarily affecting the skin and peripheral nerves. Leprosy is a major public health problem in developing countries. Children are believed to be the most vulnerable group to Mycobacterium leprae infection following long incubation period. The crucial role of frequency of leprosy in children is an indicator of the level of transmission in the community, the usual source of contact being the family members, neighbours or contact fellow students in the schools. Studies have also shown that the usual source of contact in children is from the borderline lepromatous and lepromatous leprosy cases. In children, tuberculoid leprosy is more common than lepromatous leprosy. Lepra reactions are rare and deformities due to

'Financial or Other Competing Interest': None.

Submission 13-03-2018, Peer Review 14-04-2018,

Acceptance 20-04-2018, Published 21-05-2018.

Corresponding Author:

Balaji Gopalan,

\#33, Devadoss Street,

Vedachalam Nagar,

Chengelpet-603001, Tamilnadu.

E-mail:dhunsi75@gmail.com

DOI: $10.14260 /$ jemds $/ 2018 / 576$ sensory-motor deficits are also rare. The main objective of this study was to analyse the clinico-epidemiological features of paediatric leprosy cases in our tertiary care centre.

\section{MATERIALS AND METHODS}

This is a retrospective descriptive study on 39 self-reported patients who attended Dermatology outpatient department at Thanjavur Medical College situated in Southern part of India. It was conducted during the period of 1 year from March 2017 to February 2018. The study enrolled all patients with no exclusion based on sex, nationality and socio-economic status. Details like age, sex and onset of disease were recorded. A detailed history was taken in each patient with particular reference to cutaneous conditions including duration, progression and treatment modalities. Age, sex, family history and duration of illness were recorded. The clinical features were thoroughly studied. Sensory and motor deficits of the patients were recorded. Temperature, touch and pain were the main sensations recorded. A thorough examination of peripheral nerves were done with special reference to thickening, nodularity and tenderness of the nerves. Deformities and trophic ulcers were also studied. Slit skin smear slides stained with Ziehl-Neelsen technique and histopathological slides stained with haematoxylin-eosin and Wade-Fite stains were reviewed. Smear positive cases were expressed in terms of bacteriological index and 
morphological index. After clinical examination and investigations, the leprosy cases were classified based on the Ridley-Jopling and Indian association of Leprologist's classification.(1) The data collected were analysed in terms of descriptive statistics.

\section{RESULTS}

A total of 39 paediatric leprosy cases attended Dermatology outpatient department of Thanjavur Medical College.

\section{Sex Ratio}

Out of 39 paediatric leprosy cases, 28 were male children and 11 were female children. The male-female ratio was $2.5: 1$.

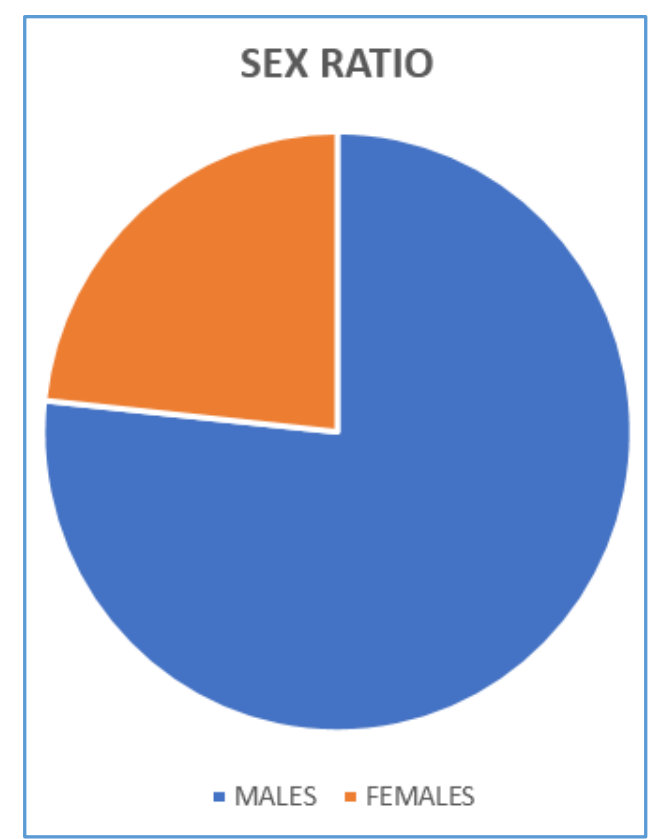

\section{Age of Onset}

The age of childhood leprosy cases detected during this study ranges from 3 to 12 years. The age group $10-12$ yrs. accounted for maximum number of cases. 27 cases were in the age group $10-12$ yrs., 9 cases lie between 7 - 9 yrs. and only 3 cases lie between $3-6$ yrs.

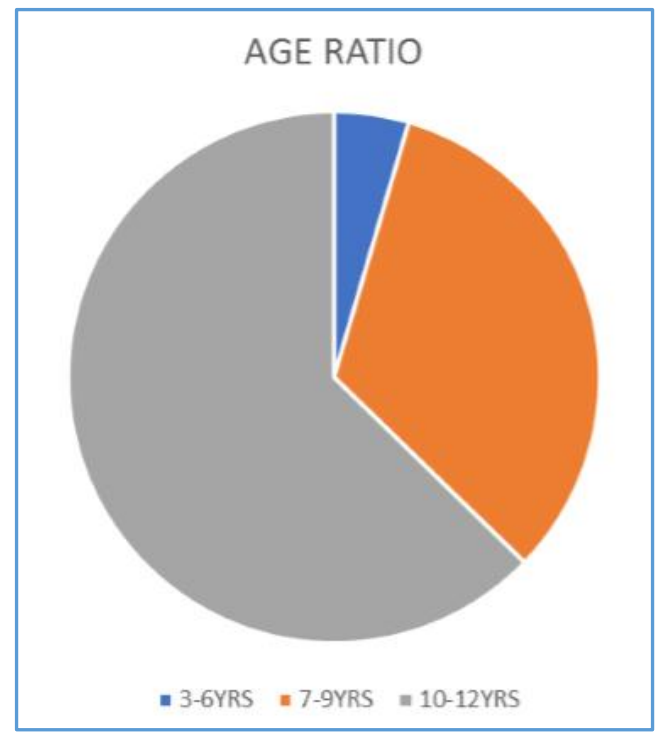

\section{Distribution of Skin Lesions}

Skin Lesions in most of the cases were located in face (19 cases) and upper limbs (8 cases). Less commonly lesions were present in trunk ( 7 cases) and lower limbs ( 5 cases).

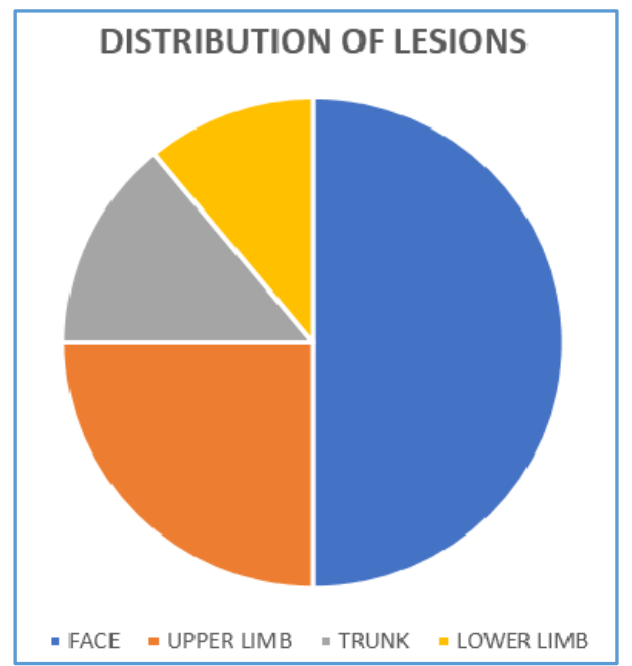

\section{Type of Leprosy}

Out of 39 Paediatric Leprosy cases, 23 cases were of borderline tuberculoid type, 11 cases were of indeterminate type, 5 cases were of tuberculoid type. There were nil lepromatous leprosy and pure neuritic leprosy cases.

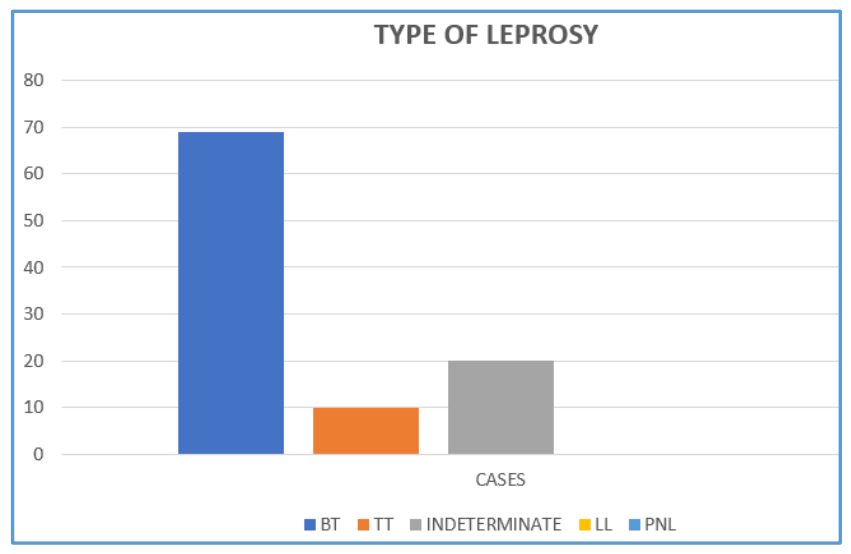

\section{Peripheral Nerve Involvement}

Clinically, thickened peripheral nerve was recorded in 27 cases. Ulnar nerve was involved in maximum number of cases (17 cases). Next to ulnar nerve, common peroneal nerve was involved in 7 cases and posterior tibial nerve in 2 cases. Radial cutaneous nerve involvement was seen only in 1 case.

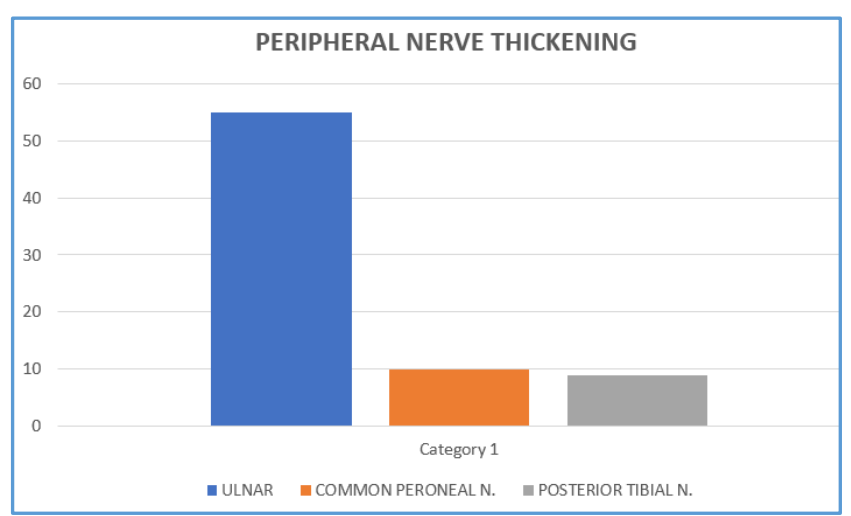




\section{History of Contact}

Out of 39 cases, 11 had history of contact with lepromatous leprosy cases. It was observed that among 11 lepromatous leprosy cases, 7 had history of contact within family and 4 had contact within their school children.

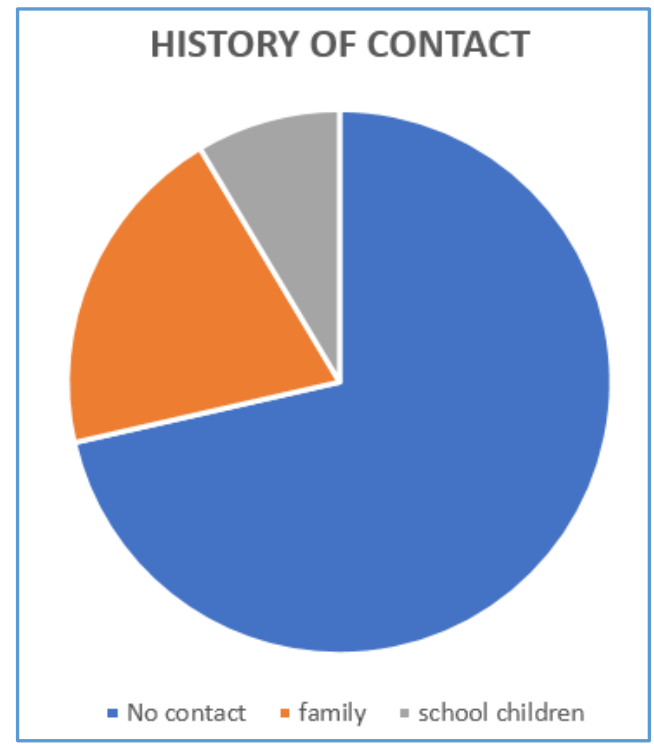

\section{Slit Skin Smear}

Among 39 paediatric leprosy cases, slit skin smear was found to be positive in 5 cases and negative in 34 cases.

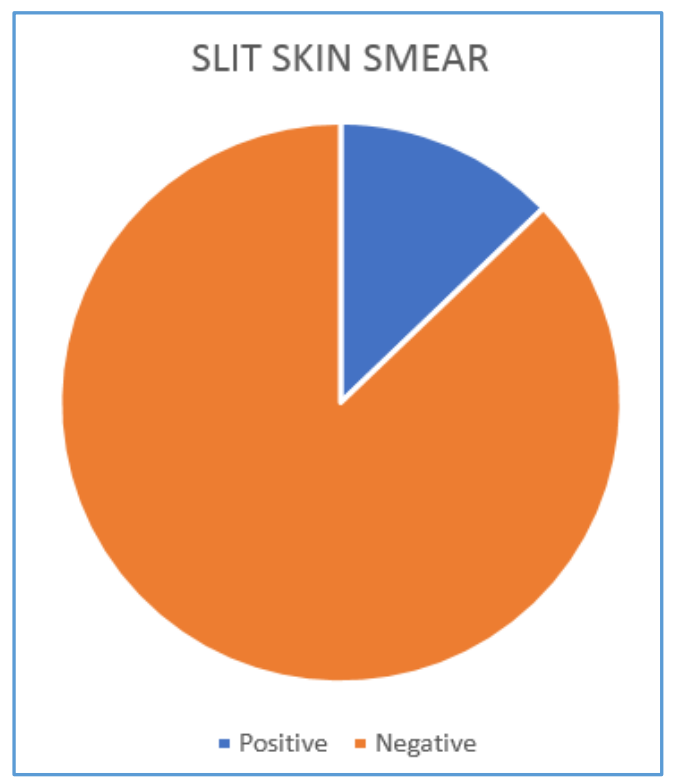

\section{Deformity}

Among 39 paediatric leprosy cases only 4 cases had deformity, constituting 3 cases of claw hand and 1 case of foot drop.

\section{DISCUSSION}

Leprosy is a chronic granulomatous disease caused by Mycobacterium leprae affecting all age groups, primarily affecting the nerves and skin and secondarily other organs. Leprosy in paediatric age group indicates a hidden reservoir of infective cases in the community, the usual source of contact being the family members, neighbours or contact from fellow students in the schools where they are studying.
The high percentage of MB contacts prevailing in the community evidently indicates the grave nature of the problem of undetected childhood leprosy, recent active transmission and highlights the implications of this on individual patients and the community. The high male-tofemale ratio amongst child leprosy cases observed in this study is similar to the findings of many studies conducted over the past few decades. The mean duration of symptoms exceeded 1 year, which can be attributed to poor knowledge of leprosy or barriers in access to health care or its utilisation. Nasal discharges from untreated lepromatous leprosy patients, who are often undiagnosed for several years are the main source of infection in the community.(2) Mycobacterium leprae is inhaled, multiplies on the inferior turbinates and has a brief bacteraemic phase before binding to Schwann cells in Peripheral nerves and macrophages in Dermis. In patients with the tuberculoid types of leprosy M. leprae remains within the skin and nerve compartments and these patients are probably never infectious.

The Diagnosis is usually made Clinically on the basis of Two out of Three Characteristic findings, or by the demonstration of AFB. The Cardinal Signs are-

1. Diminution or loss of sensation in a typical skin lesion or in an area supplied by one of the peripheral nerves typically affected in leprosy.

2. Enlargement and/or tenderness in a peripheral nerve typically affected in leprosy.

3. Demonstration of acid fast bacilli in skin smears.

The AFB load of a patient is determined by modified Ziehl-Neelsen staining of slit-skin smears.

The Pathogenesis, and thus the Clinical Features reflect Four Principal causes of Tissue Damage

1. The degree to which cell-mediated immunity (CMI) is expressed.(3) Lepromatous leprosy represents a failure of CMI. The absence of activated lymphocytes and macrophages means that nerve damage is slow and gradual in onset. In tuberculoid leprosy, CMI is strongly expressed, so that the infection is restricted to one or a few skin sites and peripheral nerves. Lymphocytic infiltration rapidly causes nerve damage.

2. The extent of bacillary spread and multiplication. In lepromatous leprosy, haematogenous spread of bacilli occurs $^{(4)}$ to cool superficial sites including eyes, upper respiratory mucosa, testes, small muscles and bones of hands, feet and face as well as peripheral nerves and skin. In tuberculoid leprosy, bacillary multiplication is restricted to a few sites and bacilli are not readily found.

3. The appearance of tissue-damaging immunological complications: lepra reactions.(5) Borderline patients (borderline tuberculoid, BT; borderline, BB; borderline lepromatous, BL) are immunologically unstable and at risk of developing immune-mediated reactions. Type 1 (Reversal) reactions are delayed hypersensitivity reactions caused by increased recognition of M. leprae antigens in skin and nerve sites. Type 2 reactions, erythema nodosum leprosum (ENL) are due in part to immune complex deposition and occur in BL and LL patients who produce antibodies and have a large antigen load. 
4. The development of nerve damage and its complications. Nerve damage occurs in two settings, in skin lesions and in peripheral nerve trunks. In skin lesions, the small dermal sensory and autonomic nerve fibres supplying dermal and subcutaneous structures are damaged causing local sensory loss and loss of sweating within the area of the skin lesion.(6) Peripheral nerve trunks are vulnerable at sites where they are superficial or are in fibro-osseous tunnels. At these points, a small increase in nerve diameter leads to raised intraneural pressure with consequent neural compression and ischaemia. Damage to peripheral nerve trunks produces characteristic signs with dermatomal sensory loss and dysfunction of muscles supplied by that peripheral nerve. Physiological evidence of central and peripheral autonomic nerve involvement has also been reported.(7,8) Nerve damage leads to anaesthesia, muscular weakness and contracture and autonomic dysfunction. These permit trauma, bruising, burns, cuts and especially tissue necrosis from prolonged, inappropriate or repetitive trauma which in turn lead to ulceration, secondary cellulitis and osteomyelitis and loss of tissue so that deformity is added to disability.

Educating a leprosy patient about their disease is the key to successful management. The patient needs to be reassured that within a few days of chemotherapy, they will not be infectious. It is important to emphasise that gross deformities are not the inevitable end point of disease, and that care and awareness of their limbs is as important as chemotherapy. Anxieties about transmission and reactions as well as issues about compliance should be addressed.

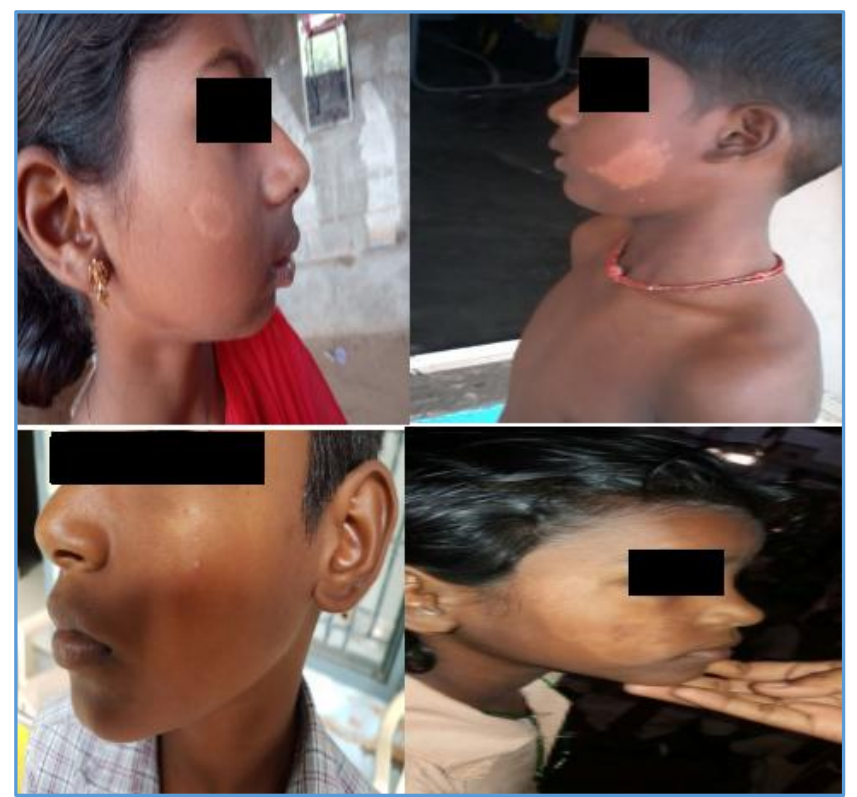

Clinical Images of Patients showing Borderline Tuberculoid Spectrum of Hansen's Disease

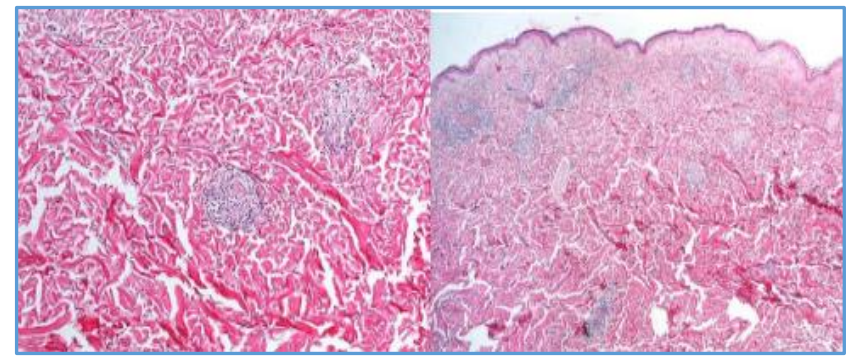

\section{Biopsy showing Granulomas in Borderline Tuberculoid} Hansen's Disease Patient

\section{CONCLUSION}

This study showed that the prevalence of paediatric leprosy cases is increasing in current scenario; age group of $10-12$ years was the most commonly affected; macules were the most common primary skin lesion; BT was the most common type of leprosy; and the prevalence of LL, lepra reactions and deformity was low.

\section{REFERENCES}

[1] Ridley DS, Jopling WH. Classification of leprosy according to immunity. A five-group system. Int J Lepr Other Mycobact Dis 1966;34(3):255-73.

[2] Pedley JC. The nasal mucus in leprosy. Lepr Rev 1973;44(1):33-5.

[3] Myrvang B, Godal T, Feek CM, et al. Immune response to mycobacterium leprae in indeterminate leprosy patients. Acta Pathol Microbiol Scand [B] Microbiol Immunol 1973;81(5):615-20.

[4] Drutz DJ, Chen TS, Lu WH. The continuous bacteremia of lepromatous leprosy. N Engl J Med 1972;287(4):159-64.

[5] Jopling WH. Reactions in leprosy. Lepr Rev 1970;41(1):62-3.

[6] Dastur DK. Cutaneous nerves in leprosy: the relationship between histopathology and cutaneous sensibility. Brain 1955;78(4):615-33.

[7] Shah PK, Malhotra YK, Lakhotia M, et al. Cardiovascular dysautonomia in patients with lepromatous leprosy. Indian J Lepr 1990;62(1):91-7.

[8] Beck JS, Abbot NC, Samson PD, et al. Impairment of vasomotor reflexes in the fingertips of leprosy patients. J Neurol Neurosurg Psychiatry 1991;54(11):965-71. 